\title{
REDOX-REGULATION OF GELATINASES DURING GROWTH OF CISPLATIN-SENSITIVE AND RESISTANT GUERIN CARCINOMA
}

\author{
A.P. Burlaka*, I.I. Ganusevich, Yu.V. Lozovska, N.Yu. Lukianova, V.F. Chekhun \\ R.E. Kavetsky Institute of Experimental Pathology, Oncology and Radiobiology, NAS of Ukraine, Kyiv 03022, Ukraine
}

Study was aimed to analyze the dynamics of changes and study interrelations between content of ferritin, transferrin, active gelatinases (MMP-2 and -9) in blood serum and tumor tissue, free iron, rate of superoxide radicals generation in tumor, activity of NADPH-oxidase and iNOS in neutrophils rats with sensitive and resistant strains of Guerin carcinoma (GC). Materials and Methods: In order to obtain resistant tumor, 12 courses of cisplatin chemotherapy have been carried out on rats bearing GC. Levels of transferrin and free iron were determined by analysis of EPR spectra from computerized radiospectrometer EPR RE-1307 at temperature of liquid nitrogen. Rate of superoxide radicals and nitric oxide generation in tumor and neutrophils of blood was determined by EPR using spin traps at room temperature. Content of ferritin in tumor homogenate and blood serum of rats with GC was determined by ELISA method using corresponding kits. Concentration of active forms of MMP-2 and -9 in obtained samples was determined using method of zymography. Results: Unregulated generation of superoxide radicals and NO by mitochondria of tumor cells and NADPH-oxidase and iNOS neutrophils via oxidation of iron-containing proteins causes the accumulation of "free iron" complexes in blood and tumor tissue of rats able to evoke oxide-induced damages of macromolecules. It has been shown that for resistant strain of carcinoma, as compared with sensitive one, significantly higher concentrations of active forms of MMP-2 and -9 in blood serum of rats are typical. Dynamics of gelatinases activity changes in tumor tissue corresponds in general with dynamics of changes in serum. In tumor tissue of rats the indices of gelatinases activity positively correlate with rate of superoxide radicals generation, content of "free iron" complexes, ferritin and activity of transferrin. Cytostatic agent increased levels of reactive oxygen species (ROS) and self-amplify rate of superoxide radicals generation. In turn, activation of MMPs via superoxide-depending regulation allows tumor cells to facilitate migration, invasion and finally - formation of metastatic centers. Mentioned above tumor "oxide phenotype" determines high level of its aggressiveness and forms corresponding level of drug resistance. Conclusions: Thus, high levels of superoxide radicals oxidize transport proteins and form free iron pool. Iron ions, via Haber - Weiss mechanism, initiate generation of the hydroxyl radicals, which also enhance oxidation processes.

Key Words: drug resistance, redox-regulation, iron-containing proteins, matrix metalloproteinases.

It is known that one of the main reasons of low effectiveness of antitumor therapy is resistance of tumors to cytostatic drugs, which action is often associated with formation of reactive oxygen species(ROS) [1, 2]. Superoxide radicals are not only directly oxidizing biological macromolecules, but also are able to interact with metals, in particular, with iron, which can intensify oxidative degradation of tumor cells [3]. Moreover, according to the results of some studies, formation of resistance to cytostatic agents is accompanied with disorder of the iron metabolism $[4,5]$ that causes intensification of oxidative effects. Upon the conditions of high levels of generation, ROS interact with membrane lipids causing changes of their permeability, oxide-induced instability of genome functioning and oxide modification of proteins that results in changing of catalytic activity of the enzymes and/or precondition of proteolytic degradation of proteins. At extreme levels of generation, ROS as molecules-messengersare able to modulate signal cascades and irreversibly change biology of cells contributing to the progression of tumor [6-10]. Among redox-regulated proteases, important place is taken by matrix metalloproteinases-2 and -9 (MMP-2 and -9), or gelatinases A and B, respectively [11-14]. These enzymes are zinc-containing endopeptidases, that have been synthesized by tumor cells and adjacent tissues, endothelial, immunocompetent cells

Submitted: October 23, 2014.

*Correspondence: E-mail: apburlaka@gmail.com Abbreviations used: GC - Guerin carcinoma; EM - extracellular matrix; EPR - electron paramagnetic resonance; MMP - matrix metalloproteinases; NO - nitric oxide; iNOS - inducible NOsynthase; ROS - reactive oxygen species. and their precursors. Zinc-containing endopeptidases provide degradation of extracellular matrix (EM) in the processes of invasion and metastasis development $[15,16]$. Thus, redox-dependent effects played important role in formation of tumor resistance to cytostatic drugs. On the one hand, they are connected with metabolism of metals, in particular iron, and on the other hand - with their impact through signal pathways on the basic factors of the vital activity of cells, including degradation of EM. On the whole, dynamics and mechanisms of such connections are not sufficiently studied, especially in vivo.

Study was aimed to analyze the dynamics of changes and study of interrelations between indices of ferritin, transferrin, gelatinases (MMP-2 and -9) content in blood serum and tumor tissue, levels of "free iron", rate of superoxide radicals generation in tumor, activity of NADPHoxidase and iNOS in neutrophils of rats with sensitive and resistant strains of Guerin carcinoma (GC).

\section{MATERIALS AND METHODS}

Eighty male rats ( $\approx 120 \mathrm{~g}$ each) with cisplatin-sensitive and resistant GC were involved in the study. GC was transplanted subcutaneously at a dose of $2 \cdot 10^{6}$ cells per animal. Resistant strain was obtained via sequential transplantations of GC after course of cisplatin chemotherapy in rats. In order to obtain resistant tumor, 12 courses of chemotherapy have been performed. All experiments were carried out according to current bioethical norms. According to the aim of study, changes of level of metalcontaining proteins in blood of animals were measured in different periods of growth of GC $-1,3,5,7,14$ and 
23 day after transplantation. $1-5^{\text {th }}$ day of tumor development is considered to be latent period of growth, $7-14^{\text {th }}$ day is referred to the phase of exponential growth, and $23^{\text {rd }}$ day - to the terminal phase of tumor growth.

Samples for analysis were frozen in special press-form in liquid nitrogen at temperature $77 \mathrm{~K}$ and EPR spectra were registered on computerized radiospectrometer EPR RE-1307 (USSR) at temperature of liquid nitrogen. Levels of transferrin and "free iron" have been determined by analysis of EPR spectra. Rate of superoxide radicals and nitric oxide generation in tumor and blood neutrophils was determined by EPR using spin-traps at room temperature $[11,14,30]$. Content of ferritin in tumor homogenate and blood serum of rats with GC was determined by ELISA method using corresponding kits: USCN (China) using Chem Well 2990 (GBG, USA) biochemical analyzer. Blood serum samples for ELISA were obtained according to kit recommendations. All samples did not contain signs of hemolysis (were centrifuged at $1500 \mathrm{rpm}$ and stored at $\mathrm{T}-20^{\circ} \mathrm{C}$ ). Homogenate of tumor tissue was obtained in saline in ratio $1 / 3$. Samples of tumor homogenate were centrifuged at $2000 \mathrm{rpm}$ and stored at $\mathrm{T}-20{ }^{\circ} \mathrm{C}$. Also, concentration of MMP-2 and -9 active forms in obtained samples was determined using zymography in polyacrylamide gel with gelatin as substrate [17].

Statistical processing was carried out using program package Statistica 6.0. Significance of differences between indices of different groups was assessed using Student's $t$-test. Differences were considered significant at $p<0.05$.

\section{RESULTS AND DISCUSSION}

In Table 1, dynamics of NADPH-oxidase and iNOS activity in rats with sensitive and resistant GC are given. Significant increase of activity of NADPH-oxidase activity in neutrophils, exceeded control values on $23^{\text {rd }}$ day after transplantation 7 times for sensitive and 8.5 times for resistant strains $(p<0.05)$ was shown. Activity of iNOS of neutrophils in rats with tumors of both strains increased 2.3 times as compared to control $(p<0.05)$.

Table 1. Rate of superoxide radicals generation by NADPH-oxidase and NO by iNOS of neutrophils in blood of rats in dynamics of GC growth

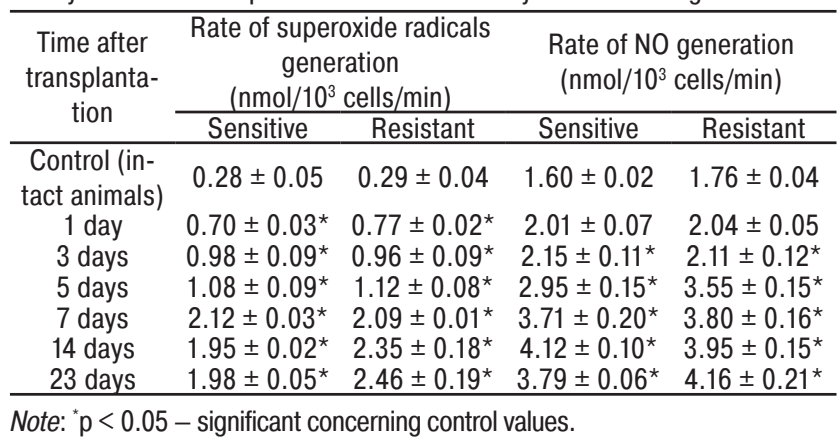

High rates of superoxide radicals generation and NO by neutrophils of blood are associated with decrease of transferrin activity in blood serum of sensitive and resistant strains of GC (Table 2).

In blood serum of rats with sensitive tumor, as early as on $1^{\text {st }}$ day after transplantation essential decrease of transferrin activity was observed as compared to control. Later on, decrease of transferrin activity from $0.67 \pm$
0.06 r.u. on the $1^{\text {st }}$ day to $0.16 \pm 0.07$ r.u. on $23^{\text {rd }}$ day after transplantation took place, i.e., 6 times on the whole compared with control $(p<0.05)$. At the same time, transferrin activity in tumor was increased - from $0.1 \pm 0.05$ r.u. on $7^{\text {th }}$ day to $0.5 \pm 0.05$ on $23^{\text {rd }}$ day after transplantation, i.e. 5 times $(p<0.05)$ (see Table 2). In blood serum and tumor tissue of resistant strain, changes of transferrin activity was occurred. Obtained results coincide with data on transferrin receptors hyperexpression in tumor cells [18-20] and increased content of transferrin in resistant tumor cells cultivation medium [21].

Table 2. Transferrin activity in tumor tissue and blood serum of animals with GC on different stages of its development

\begin{tabular}{ccccc}
\hline Time after & \multicolumn{4}{c}{ Activity of transferrin (r.u.) } \\
\cline { 2 - 5 } transplanta- & \multicolumn{2}{c}{ Sensitive strain } & \multicolumn{2}{c}{ Resistant strain } \\
\cline { 2 - 5 } tion & serum & tumor & serum & tumor \\
\hline Control (in- & $0.93 \pm 0.07$ & - & $0.88 \pm 0.1$ & - \\
tact animals) & & & & \\
1 day & $0.67 \pm 0.06^{\star}$ & - & $0.82 \pm 0.21$ & - \\
3 days & $0.55 \pm 0.04$ & - & $0.64 \pm 0.12$ & - \\
5 days & $0.48 \pm 0.12$ & - & $0.58 \pm 0.10$ & - \\
7 days & $0.35 \pm 0.03$ & $0.1 \pm 0.05$ & $0.47 \pm 0.12^{\star}$ & $0.15 \pm 0.05$ \\
14 days & $0.24 \pm 0.05$ & $0.3 \pm 0.09$ & $0.39 \pm 0.20^{\star}$ & $0.42 \pm 0.12$ \\
23 days & $0.16 \pm 0.07^{\star}$ & $0.5 \pm 0.05^{\star \star}$ & $0.21 \pm 0.04^{\star}$ & $0.58 \pm 0.05^{\star \star}$ \\
\hline
\end{tabular}

Note: ${ }^{*} p<0.05$ - significant concerning control values; ${ }^{* \star} p<0.05-$ significant concerning values on the $7^{\text {th }}$ day.

In contrast, ferritin level (Table 3) in blood serum of rats with tumors of both sensitive and resistant strains was increased starting from the $1^{\text {st }}$ to $7^{\text {th }}$ day, exceeding control values 1.3 times $(p<0.05)$. In tumors of sensitive and resistant strains, the highest level of ferritin was observed on the $14^{\text {th }}$ day after transplantation. Indices for resistant strains were 2 times higher than for sensitive strain. Results of studies are confirmed by literature data. In particular, it is known that in blood of patients with lung cancer and neuroblastoma, increased levels of ferritin are observed and are associated with aggressiveness of tumor [22]. Also, some authors observed its accumulation in tumor cells [23-26].

Table 3. Content of ferritin in tumor tissue and blood serum of animals with GC on different stages of its development

\begin{tabular}{ccccc}
\hline Time after & \multicolumn{4}{c}{ Ferritin content } \\
\cline { 2 - 5 } transplanta- & \multicolumn{3}{c}{ Sensitive strain } & \multicolumn{2}{c}{ Resistant strain } \\
\cline { 2 - 5 } tion & serum $(\mathrm{ng} / \mathrm{ml})$ & tumor $(\mathrm{ng} / \mathrm{g})$ & serum $(\mathrm{ng} / \mathrm{ml})$ & tumor $(\mathrm{ng} / \mathrm{g})$ \\
\hline Control (in- & $13.78 \pm 0.18$ & - & $13.40 \pm 1.40$ & - \\
tact animals) & & & & \\
1 day & $14.21 \pm 0.11$ & - & $14.10 \pm 1.80$ & - \\
3 days & $14.79 \pm 0.23$ & - & $14.50 \pm 1.30$ & - \\
5 days & $15.31 \pm 0.15$ & - & $14.86 \pm 2.89$ & - \\
7 days & $18.54 \pm 0.06^{\star}$ & $6.19 \pm 0.02$ & $17.50 \pm 1.72^{*}$ & $14.91 \pm 2.72$ \\
14 days & $16.25 \pm 0.45^{\star}$ & $9.43 \pm 0.02^{\star *}$ & $11.33 \pm 0.32^{*}$ & $19.13 \pm 0.90^{*}$ \\
23 days & $17.98 \pm 0.28^{\star}$ & $7.34 \pm 0.12$ & $11.16 \pm 0.98$ & $17.23 \pm 0.98$ \\
\hline
\end{tabular}

Note: ${ }^{*} p<0.05-$ significant concerning control values; ${ }^{\star \star} p<0.05-$ significant concerning values on the $7^{\text {th }}$ day.

In tumors of sensitive and resistant strains starting from the $7^{\text {th }}$ to $23^{\text {rd }}$ day after transplantation significant increase of "free iron" complexes content was observed (in 10 times; $p<0.05$ ) and it was associated with increase of superoxide radicals generation rate in tumor tissue of sensitive and resistant strain ( 1.1 and 1.2 times, respectively; $p>0.05$ ) (Table 4).

Thus, increased generation of superoxide radicals and NO by NADPH-oxidase and iNOS in neutrophils via oxidation of iron-containing proteins causes the accumulation of "free iron" complexes in blood and tumor tissue of rats able 
to evoke oxide-induced damages of macromolecules. Such changes in metabolism are enhanced even more at use of cytostatics and cause intensification of oxide damages of membranes, DNA and proteins causing critical disorders of the foundations of vital activity of cells, in particular, deregulation of EM destruction [11, 16]. Taking into account this observation, we have determined levels of MMP-2 and -9 active forms in blood serum and tumor tissue of rats. Comparative analysis of changes of activity of MMP-2 in blood serum of rats with sensitive and resistant strains of GC demonstrates the lack of enzyme activity till $7^{\text {th }}$ day after transplantation inclusively (Fig. 1). From $8^{\text {th }}$ to $23^{\text {rd }}$ day, significant increase of concentration of active MMP-2 in blood serum of rats with tumors of both strains was observed, but these indices were significantly higher for resistant strain $-2-2.5$ times on the whole as compared with sensitive strain $(p<0.05)$.

Table 4. Content of "free iron" complexes and rate of superoxide radicals generation in GC on different stages of growth

\begin{tabular}{|c|c|c|c|c|}
\hline \multirow{2}{*}{$\begin{array}{l}\text { Time after } \\
\text { transplanta- } \\
\quad \text { tion }\end{array}$} & \multicolumn{2}{|c|}{ "Free iron" complexes (r.u.) } & \multicolumn{2}{|c|}{$\begin{array}{l}\text { Rate of superoxide radicals } \\
\text { generation in tumor tissue } \\
\text { (nmol/g of raw tissue/min) }\end{array}$} \\
\hline & Sensitive & Resistant & Sensitive & Resistant \\
\hline $7 \mathrm{daj}$ & 0.19 & & & \\
\hline 14 & $.05^{\star}$ & $0.68 \pm$ & $0.51 \pm 0.1$ & 0.18 \\
\hline 23 days & $1.95 \pm 0.08^{\star}$ & $2.00 \pm 0.08^{\star}$ & $0.56 \pm 0.09$ & $0.64 \pm 0.11$ \\
\hline
\end{tabular}

Note: ${ }^{*} p<0.05-$ significant concerning values on the $7^{\text {th }}$ day.

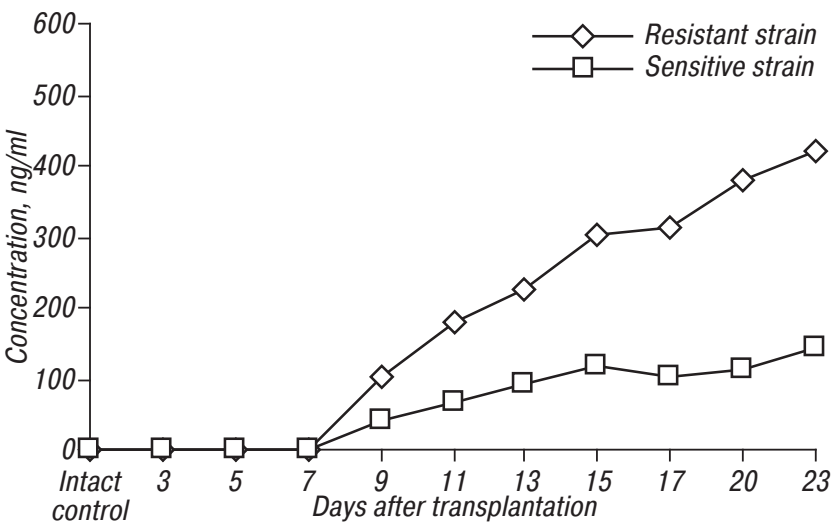

Fig. 1. Concentration of MMP-2 active forms in blood serum of rats with sensitive and resistant GC

Comparative analysis of changes of MMP-9 activity in blood serum of rats with sensitive and resistant strains of GC demonstrated the lack of activity of enzyme till $5^{\text {th }}$ day after transplantation inclusively only for sensitive strain (Fig. 2). In blood serum of rats with resistant strain, increase of MMP-9 active forms concentration was observed from $3^{\text {rd }}$ day to $23^{\text {rd }}$ day after transplantation. Values for both strains increased and achieved maximal values on the $14^{\text {th }}-15^{\text {th }}$ day with slight decrease before $23^{\text {rd }}$ day after transplantation, but they were 2-3 times higher for resistant strain, than for sensitive one $(p<0.05)$.

Thus, it was shown that significantly higher concentrations of active forms of MMP-2 and -9 in blood serum of rats were typical for resistant strain, as compared to sensitive one. Dynamics of gelatinases active form concentrations changes in tumor tissue is associated in general with dynamics in serum (Table 5).

Direct positive correlation between concentration of gelatinases active forms in blood serum and activity of NADPH-oxidase and iNOS in neutrophils $(r=0.67$; $p<0.05$ ) was shown (Table 6). At the same time, concentrations of MMP-2 and -9 active forms inversely correlated with transferrin activity in blood $(r=-0.72$ and -0.63 , respectively; $p<0.05$ ) that was explained by decrease of concentration of gelatinases active forms in dynamics of tumor growth (see Table 2).

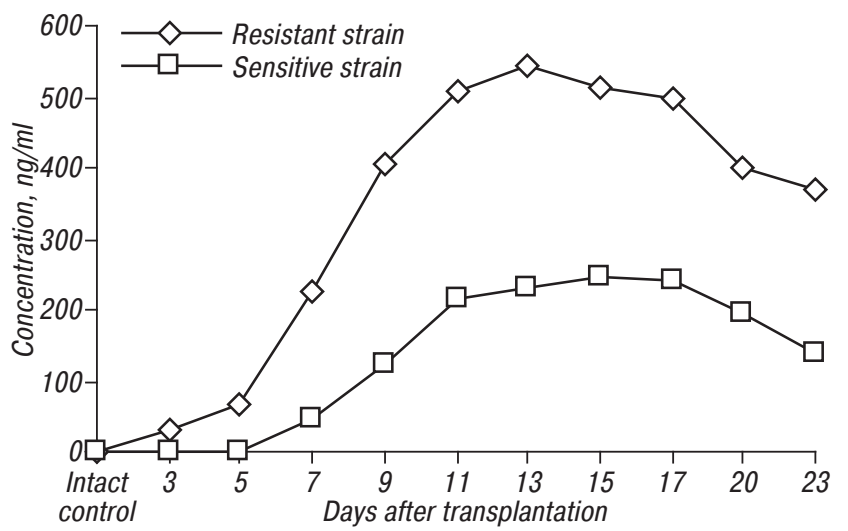

Fig. 2. Concentration of MMP-9 active forms in blood serum of rats with sensitive and resistant GC

Table 5. Concentrations of MMP-2 and -9 active forms in sensitive and resistant GC

\begin{tabular}{ccccc}
\hline Time after & \multicolumn{2}{c}{ MMP-2, $\mu \mathrm{g} / \mathrm{g}$} & \multicolumn{2}{c}{ MMP-9, $\mu \mathrm{g} / \mathrm{g}$} \\
\cline { 2 - 5 } $\begin{array}{c}\text { transplanta- } \\
\text { tion, days }\end{array}$ & Sensitive & Resistant & Sensitive & Resistant \\
\hline 7 & $0.5 \pm 0.2$ & $2.8 \pm 0.9$ & $1.2 \pm 0.5$ & $4.2 \pm 1.4$ \\
14 & $1.5 \pm 1.0$ & $4.0 \pm 1.7$ & $4.8 \pm 1.8^{\star}$ & $10.5 \pm 3.8^{\star}$ \\
23 & $2.6 \pm 0.8$ & $3.2 \pm 1.8$ & $2.2 \pm 0.3^{\star}$ & $8.4 \pm 3.5$ \\
\hline
\end{tabular}

Note: ${ }^{*} p<0.05-$ significant as compared with $7^{\text {th }}$ day.

Table 6. Correlation between levels of gelatinases and redox-associated indices in blood (B) or tumor tissue (TT) of rats with GC (sensitive and resistant)

\begin{tabular}{lcc}
\hline \multicolumn{1}{c}{ Redox-associated indices } & MMP-2 & MMP-9 \\
\hline Transferrin activity (B) & $r=-0.72$ & $r=-0.63$ \\
Activity of NADPH-oxidase & $r=0.74$ & $r=0.81$ \\
of neutrophils (B) & $r=0.67$ & $r=0.77$ \\
Activity of iNOS in neutrophils (B) & $r=0.87$ & $r=0.85$ \\
Rate of superoxide radicals generation (TT) & $r=0.54$ & $r=0.31$ \\
"Free iron" complexes (TT) & $r=0.87$ & $r=0.82$ \\
Ferritin content (TT) & $r=0.74$ & $r=0.62$ \\
Transferrin activity (TT)
\end{tabular}

In tumor tissue, concentration of gelatinases active forms positively correlated with rate of superoxide radicals generation, content of "free iron" complexes, ferritin and activity of transferrin (see Table 6). It is known that during invasion and metastasis tumor cells are involved in series of interactions with EM and its proteins, growth factors, cytokines, basal membranes, endothelial cells, circulating blood cells, microenvironment of secondary site, where tumor cells finally replace normal tissues and form metastatic focus. MMPs, in particular MMP-2 and -9 (gelatinases), that are produced both by tumor and stromal cells and via remodeling of EM proteins help tumor cells to overcome physical barriers and provide them with their regulatory and communicative properties $[15,16]$. Thus, MMPs are the important factor of survival of tumor cells and development of their resistance to damaging agents, in particular to the effect of antitumor drugs. Some modern studies in vitro demonstrated that doxorubicin-resistant tumor cells were characterized by higher levels of MMPs activity, than sensitive cells $[27,28]$. Probably, high activity of gelatinases provided survival of tumor cells during tumor invasion and metastasis development. 
Thus, development of resistance includes formation of so called "oxide phenotype" of cells. It is known that dysfunction of mitochondria is connected with initiation of developmentand progression of malignant tumors [29]. Upon these conditions, mitochondria and NADPH-oxidase are the main producers of high levels of superoxide radicals. Superoxide radicals, besides performing functions of signal molecules, cause oxide modifications of structural components of cells, DNA and proteins [30], in particular, transferrin, ferritin and heme-containing proteins, which provide iron metabolism. Thus, high levels of superoxide radicals oxidize transport proteins and form free iron pool. Iron ions, via Haber - Weiss mechanism, initiate generation of the hydroxyl radicals, which also enhance oxidation processes [31]. Moreover, chemotherapeutic drugs, when accumulating in mitochondria, damage electrotransportchain and intensify ROS generation and oxide damages of DNA in mitochondria and nucleus. In turn, MMP activation via superoxide-depending regulation allows tumor cells to adjust to different environmental conditions, to facilitate migration, invasion and finally — formation of metastatic foci [32]. Totality of mentioned above signs forms "oxide phenotype" of tumor, which determines high level of its aggressiveness and forms corresponding level of drug resistance.

The study is performed in terms of the topic №2.2.5.361 "Molecular epidemiology of metal-containing proteins in tumor-host interactions" of the target research program "Functional genomics and metabolomics in system biology" (2012-2016).

\section{REFERENCES}

1. Efferth $T$, Benakis A, Romero MR, et al. Enhancement of cytotoxicity of artemisinins toward cancer cells by ferrous iron. Blood 1990; 94: 3593-603.

2. Minotti G, Menna P, Salvatorelli E, et al. Antiproliferative and apoptosis inducing effect of lactoferrin and black tea polyphenol combination on hamster buccal pouch carcinogenesis. Biochim Biophys Acta 2006; 1760: 1536-44.

3. Chekhun VF, Shpilevaya SI. Role of endogenous iron in formation of tumor sensitivity to antitumor therapy. Vopr. Onkol. 2010; 56: 251-61 (in Russian).

4. Saprin AN, Kalinina EV, Serezhenkov VA, et al. Changes in the free-radical state and the level of free iron during the development of drug resistance in tumor cells. Biofizika 2006; 51: 485-90 (in Russian).

5. Tsiftsoglou AS, Tsamadou AI, Papadopoulou LC. Heme as key regulator of major mammalian cellular functions: Molecular, cellular, and pharmacological aspects. Pharmacol Therap 2006; 111: $327-45$.

6. Gauron C, Rampon C, Bouzaffour M, et al. Sustained production of ROS triggers compensatory proliferation and is required for regeneration to proceed. Sci Rep 2013; 2084: 123-33.

7. Weinberg F, Hamanaka R, Wheaton WW, et al. Mitochondrial metabolism and ROS generation are essential for Krasmediated tumor igenicity. PNAS 2010; 107: 8788-93.

8. Shimokawa $H$. Reactive oxygen species promote vascular smooth muscle cell proliferation. Circul Res 2013; 113: 1040-2.

9. Circu ML. Reactive oxygen species, cellular redox systems and apoptosis. Free Radic Biol Med 2010; 48: 749-62.

10. Zhou Y, Yan H, Guo M, et al. Reactive oxygen species in vascular formation and development. Oxid Med Cell Longev 2013; 2013: 2013-4.

Copyright (C) Experimental Oncology, 2015
11. Burlaka AP, Ganusevich II, Lukyanchuk EA, et al. Mitochondrial redox-control of matrix metalloproteinases and metastasis in patients with breast cancer. Onkologiya 2010; 12: 377-82 (in Ukrainian).

12. Burlaka AP, Ganusevich II, Gafurov MR, et al. Electron paramagnetic resonance study of tumor affected bone marrow. Cancer Microenvironment 2013; 6: 273-6.

13. McCormick ML, Gavrila D, Weintraub NL. Role of oxidative stress in the pathogenesis of abdominal aortic aneurysms. Arterioscler Thromb Vasc Biol 2007; 28: 1432-8.

14. Burlaka AP, Sydoryk EP, Ganusevich II, et al. Effects of oxygen and nitric oxide radical forms: formation of cellular hypoxia and activation of matrix metalloproteinases. Exp Oncol 2006; 1: 49-53.

15. Fingleton B. Matrix metalloproteinases: role sin cancer and metastasis. Front Biosci 2006; 11: 479-91.

16. Ganusevich II. Role of matrix metaloproteinases (MMP) at malignant neoplasms. Characteristics of MMP, regulation of their activity, prognostic value. Onkologiya 2010; 12: 10-6 (in Ukrainian).

17. DeClerk YA, Perez N, Shimada H, et al. Inhibition of invasion and metastasis in cells transfected with an inhibitor of metalloproteinases. Cancer Res 1992; 52: 701-8.

18. Prutki M, Poljak-Blazib M, Jakopovica M, et al. Alfered iron metabolism, transferring receptor 1 and ferritin in patients with colon cancer. Cancer Letters 2006; 238: 188-96.

19. Richardson DR, Ponka P. The molecular mechanism of the metabolism and transport of iron in normal an neoplastic cells. Biochim Biophys Acta 1997; 1331: 1-40.

20. Wada S, Noguchi T, Takeno S, et al. PIK3CA and TFRC located in $3 \mathrm{q}$ are new prognostic factors in esophageal squamous cell carcinoma. Ann Surg Oncol 2006; 13: 961-6.

21. Dowling P, Maurya P, Meleady P, et al. Purification and identification of $7.6 \mathrm{kDa}$ protein in media conditioned by superinvasive cancer cells. Anticancer Res 2007; 27: 1309-17.

22. Yildirim A, Meral M, Kaynar H, et al. Relationship between serum levels of some acute-phase proteins and stage of disease and performance status in patients with lung cancer. Med Sci Monit 2007; 13: 195-200.

23. Alberghini A, Recalcati S, Tacchini L, et al. Loss of the von Hippel Lindau tumor suppressor disrupts iron homeostasis in renal carcinoma cells. J Biol Chem 2005; 280: 30120-8.

24. Koc M, Taysi S, Sezen O, et al. Levels of some acute-phase proteins in the serum of patients with cancer during radiotherapy. Biol Pharm Bull 2003; 26: 1494-7.

25. Gaetano C, Vezzoni P, Bardella L, et al. Regulation of ferritin synthesis in malignant and non-malignant lymphoid cells. Biochem Biophys Res Comm 1986; 139: 652-7.

26. Pham F, Bubici $C$, Zazzeroni F, et al. Subcellular distribution of chelatable iron: a laser scanning microscopic study in isolated hepatocytes and liver endothelial cells. Biochem J 2001; 356: 61-69.

27. Kang JH, Song KH, Jeong KC, et al. Involvement of Cox-2 in the metastatic potential of chemotherapy-resistant breast cancer cells. BMC Cancer 2011; 4: 334-39.

28. Srivastava RK, Kurzrock R, Shankar S. MS-275 sensitizes TRAIL-resistant breast cancer cells, inhibits angiogenesis and metastasis, and reverses epithelial-mesenchymal transition in vivo. Mol Cancer Ther 2010; 9: 3254-66.

29. Sotgia F, Martinez-Outschoorn UE, Lisanti MP. Mitochondrial oxidative stress drives tumor progression and metastasis: should we use antioxidants as a key component of cancer treatment and prevention? BMC Medicine 2011; 9: 1741-51.

30. Burlaka AP, Sydoryk EP. Radical oxygen and nitric oxide forms at tumor process. Kyiv: Naukova Dumka, 2006. 227 p.

31. Torti SV, Torti FM. Iron and cancer: more or to be mined. Iron Cancer Nature 2013; 13: 342-55. 